\title{
Experimental vibration test of the cycloidal gearbox with different working conditions
}

\author{
Marcin Wikło $^{1}$, Olejarczyk Krzysztof ${ }^{2}$, Kołodziejczyk Krzysztof ${ }^{3}$, Kazimierz Król ${ }^{4}$, \\ Iwona Komorska ${ }^{5}$ \\ 1,2,3, ${ }^{4}$ Kazimierz Pulaski University of Technology and Humanities Institute of Applied Mechanics and \\ Energetics, Radom, Poland \\ ${ }^{5}$ Kazimierz Pulaski University of Technology and Humanities Institute of Maintenance of Vehicles and \\ Machines, Radom, Poland \\ ${ }^{1}$ Corresponding author

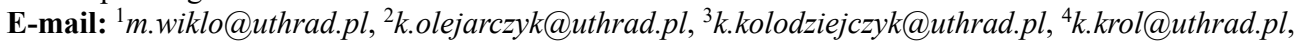 \\ 5i.komorska@uthrad.pl
}

Received 6 September 2017; accepted 7 September 2017

DOI https://doi.org/10.21595/vp.2017.19073

Check for updates

\begin{abstract}
The article undertakes the problem of vibrations induced in the cycloidal gearbox. The gearbox was calculated, designed and tested by the article authors. To perform the test a testing bench was built. The bench includes electric motors, torque meters and application to control working parameters. The input engine works at constant velocity mode and the braking unit with constant torque mode. The test was made for different configuration of working parameters.
\end{abstract}

Keywords: cycloidal gearbox, vibration, backlash.

\section{Introduction}

The cycloidal gearboxes are mainly used in the heavy machines because of their overload capability and large reduction ratio in one stage. The biggest advantages of the cycloidal gears are a small backlash, a large reduction ratio and a high accuracy. Because of these features, they are increasingly used in robotics, especially in positioners and multi-axis robots in the first joints, where stiffness is more desirable than a small mass.

Big reduction ratio connected with the relatively high velocities on the gear output requires large input speed which causes a problem with the vibration, additionally the general principle of the gear work impose vibration problems. Despite this, the literature is rather poor in articles dedicated to cycloidal gearbox vibrations.

In the literature, some research can be found, including studies dedicated to operational principles, the generation of the cycloid shape and analytical calculations of the gear with geometrical relations [1-3]. The empirical equation relating to machining tolerance with backlash and effective torque ripple was presented in [4] and a mathematical model that includes kinematics parameters and machining step to output moment calculations compared with experimental data was studied in [5]. Propositions of a cycloid generation with the elimination of lobes undercutting was proposed at [6-11]. There is also some work dedicated to the power loss and efficiency calculation [12-14]. The article [15] tries to give a unified approach to the designer how to optimize any cycloidal gear in comparison to other gear transmissions. The research [16] presents a comparison of the one stage gears - cycloidal and harmonic - in robotics.

\section{Model}

The tests were performed on the cycloidal gearbox (Fig. 1) calculated, designed and assembled at the University of Technology and Humanities in Radom.

The input shaft (1) is mounted eccentrically to cylindrical roller bearings, causing the cycloidal disc (3) to move in a circle. The cycloidal disc (3) independently rotates around the bearing as it is pushed against the housing. This is similar to planetary gearboxes and the direction of rotation is opposite to that of the input shaft. The number of external pins (4) on the housing is larger than the number of pins on the cycloidal disc. This causes the cycloidal disc (3) rotates around the 
bearing faster than the input shaft is moving it around, giving an overall rotation in the direction opposing the rotation of the input shaft. The cycloidal disc has holes that are larger than the output roller pins mounted on the output shaft (6) that go inside them. The output pins move around in the holes to achieve steady rotation of the output shaft (6) from the wobbling movement of the cycloidal disc

The backlash of the gear was changed with the use of the two pairs of the cycloidal discs. The first pair of the disc has the external cycloid profile at the middle of the tolerance, the profile was offset from nominal one. In second pair, external profile of the cycloidal surface was at nominal dimension and it was tolerated at a minus, additionally, modification of the diameter of the holes for output pins was introduced.

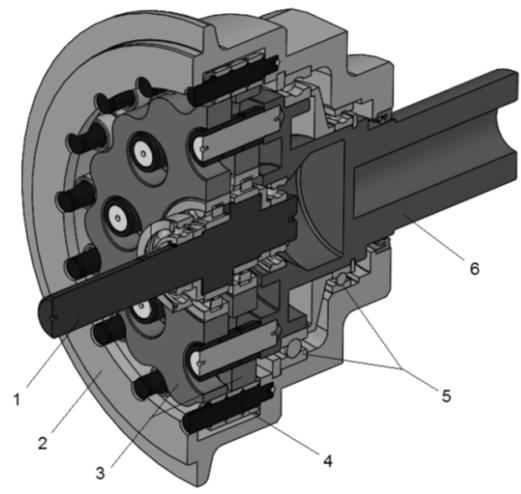

Fig. 1. Cycloidal gear cross-section, isometric view: 1 - input shaft, 2 -housing, 3 - two cycloidal discs, 4 - external pins, 5 - bearing, 6 - output shaft with internal pins

\section{Test bench}

The gear was placed on the steel plate with a set of threaded holes which allow the change the configuration of the bench - Fig. 2. The input and output motors were supported on stiff brackets as well as the cycloidal gear. The brackets ensure bench axis alignment. On the input and output of the gear, the torque meters were mounted between elastic couplings. The bench was equipped with four thermocouples. Two of them are mounted inside the gear at the bottom and at the top. Two of thermocouples are mounted via magnets and can be placed on the side of the gear or at the support and can be used to measure ambient temperature.

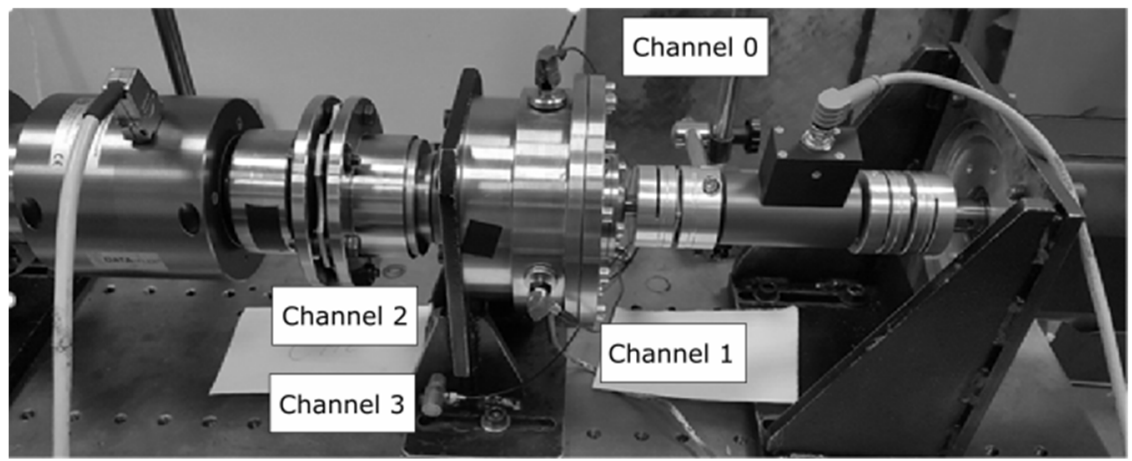

Fig. 2. Placement of the accelerometers with the channel numbers

\section{Results}

The measurements were made for the series of test with different input speed velocity 
(500 rpm-4500 rpm) and braking torque from no load to $42 \mathrm{Nm}$. An example of the results of the vibration measurement in the time domain (Fig. 3) and frequency domain (Fig. 4) proofs that the reduction of the clearance in the cycloidal gearbox reduces the amplitude of the vibration.
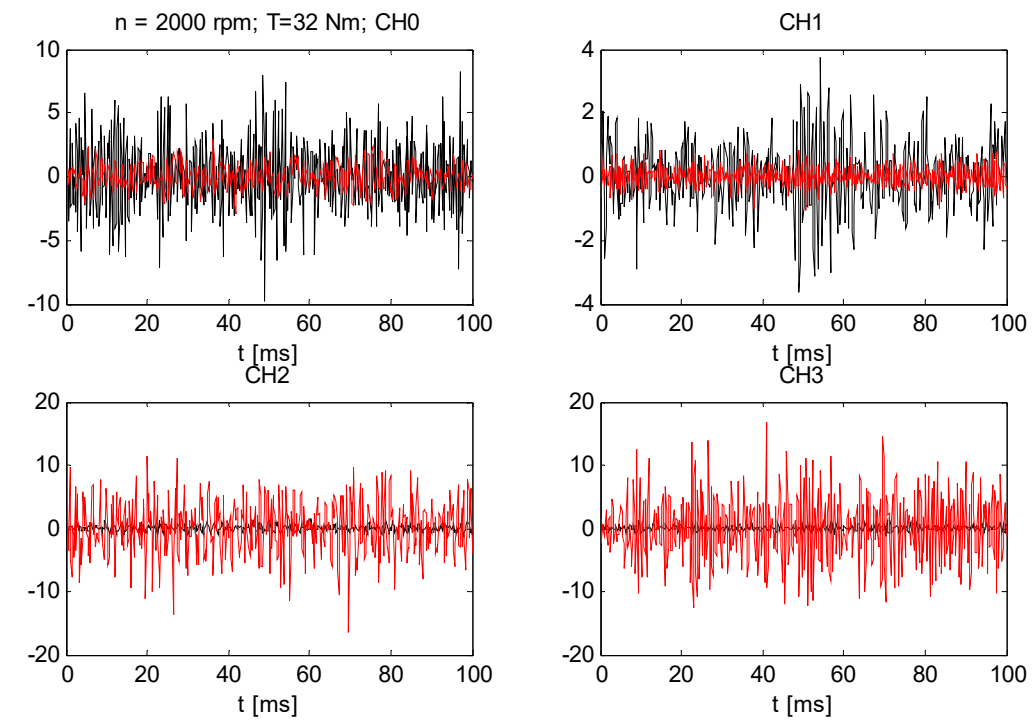

Fig. 3. Comparison of vibration waveforms for small and big clearance

(Red - big clearance; Black - small clearance) for $2000 \mathrm{rpm}$ and $38 \mathrm{Nm}$ load torque
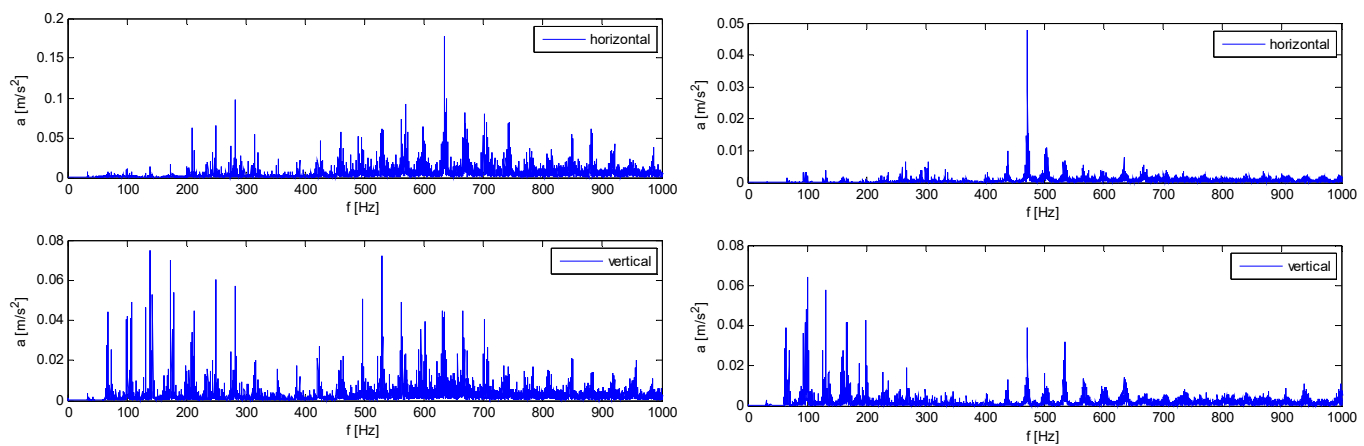

Fig. 4. Spectrum of horizontal and vertical vibrations for $2000 \mathrm{rpm}$ and $32 \mathrm{Nm}$ load torque

The identified mesh frequency can be calculated as:

$M_{f}=\frac{n_{\text {inp }}}{60} * \frac{n_{t}}{i} * n_{o p}$

where: $n_{\text {inp }}$ is input speed, $i=15$ is gear ratio, $n_{t}=16$ is number of teeth and $n_{o p}=8$ is number of output pins.

\section{Conclusions}

The problem of the vibration of the cycloidal gearbox was presented in the article. The results show strong interaction between a number of external and internal pins but the external pins have biggest influence for the amplitude and for the torque fluctuation.

Additionally, an influence of the backlash to the vibration was considered. The backlash was introduced to the gear with change the cycloidal discs and the diameter of the output pin hole. The 
tests were performed with different load conditions.

\section{References}

[1] V. N. Kudryavtsev Planetary Transmission. Mech. Eng., Leningrad, 1966, (in Russian).

[2] M. Chmurawa, Cycloidal gears with tooth modification. Silesian Technical University, Zeszyty naukowe, Vol. 1547, 2002, (in Polish).

[3] Litvin F. L., Pin H. F. Computerized design and generation of cycloidal gearings. Mechanism and Machine Theory, Vol. 31, Issue 7, 1996, p. 891-911.

[4] Blanche J. G., Yang D. C. H. Cycloid drives with machining tolerances. Journal of Mechanisms, Transmissions, and Automation in Design, Vol. 111, Issue 3, 1989, p. 337-344.

[5] Meng Y., Wu C., Ling L. Mathematical modeling of the transmission performance of 2K-H pin cycloid planetary mechanism. Mechanism and Machine Theory, Vol. 42, Issue 7, 2007, p. 776-790.

[6] Shung J. B., Pennock G. R. Geometry for trochoidal-type machines with conjugate envelopes. Mechanism and Machine Theory, Vol. 29, Issue 1, 1994, p. 25-42.

[7] Blagojevic M., Marjanovic N., Djordjevic Z., Stojanovic B., Disic A. A new design of a two-stage cycloidal speed reducer. Journal of Mechanical Design, Vol. 133, Issue 8, 2011, p. 85001.

[8] Shin J. H., Kwon S. M. On the lobe profile design in a cycloid reducer using instant velocity center. Mechanism and Machine Theory, Vol. 41, Issue 5, 2006, p. 596-616.

[9] Hwang Y.-W., Hsieh C.-F. Geometric design using hypotrochoid and nonundercutting conditions for an internal cycloidal gear. Journal of Mechanical Design, Vol. 129, 2007, p. 4-413.

[10] Hwang Y. W., Hsieh C. F. Determination of surface singularities of a cycloidal gear drive with inner meshing. Mathematical and Computer Modelling, Vol. 45, Issues 3-4, 2007, p. 340-354.

[11] Chen B., Zhong H., Liu J., Li C., Fang T. Generation and investigation of a new cycloid drive with double contact. Mechanism and Machine Theory, Vol. 49, 2012, p. 270-283.

[12] Malhotra S. K., Parameswaran M. A. Analysis of a cycloid speed reducer. Mechanism and Machine Theory, Vol. 18, Issue 6, 1983, p. 491-499.

[13] Sensinger J. W. Efficiency of high-sensitivity gear trains, such as cycloid drives. Journal of Mechanical Design, Vol. 135, Issue 7, 2013, p. 71006.

[14] Olejarczyk K., Wikło M., Kołodziejczyk K., Król K., Nowak R. Experimental impact studies of the application mineral oil and synthetic oil on the efficiency of the single-gear cycloidal. Tribologia Vol. 1, 2017, p. 67-73.

[15] Sensinger J. W. Unified approach to cycloid drive profile, stress, and efficiency optimization. Journal of Mechanical Design, Vol. 132, 2010, p. 2-24503.

[16] Sensinger J. W., Lipsey J. H. Cycloid vs. harmonic drives for use in high ratio, single stage robotic transmissions. The International Conference on Robotics and Automation, Vol. 606, Issue 11, 2012, p. 4130-4135. 